OPEN

SUBJECT AREAS:

CLIMATE-CHANGE

ECOLOGY

COMMUNITY ECOLOGY

Received

13 August 2013

Accepted

1 November 2013

Published

21 November 2013

Correspondence and requests for materials should be addressed to

M.I.M. (mark. mccormick@jcu.edu.

\title{
Ocean acidification reverses competition for space as habitats degrade
}

\author{
Mark I. McCormick, Sue-Ann Watson \& Philip L. Munday
}

ARC Centre of Excellence for Coral Reef Studies and School of Marine and Tropical Biology, James Cook University, Townsville, Queensland, Australia.

How marine communities are affected by $\mathrm{CO}_{2}$-induced climate change depends on the ability of species to tolerate or adapt to the new conditions, and how the altered characteristics of species influence the outcomes of key processes, such as competition and predation. Our study examines how near future $\mathrm{CO}_{2}$ levels may affect the interactions between two damselfish species known to compete for space, and the effects of declining habitat quality on these interactions. The two focal species differed in their tolerance to elevated $\mathrm{CO}_{2}$, with the species that is competitively dominant under present day conditions being most affected. Field experiments showed that elevated $\mathrm{CO}_{2}(945 \mu \mathrm{atm})$ reversed the competitive outcome between the two species with mortal consequences, and this reversal was accentuated in degraded habitats. Understanding these complex interactions will be crucial to predicting the likely composition of future communities under ocean acidification and climate change.

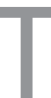

he impact of climate change on marine communities will depend on how species' differences in physiological tolerances and performance alter biological interactions within a changing resource landscape $\mathrm{e}^{1-3}$. Rising atmospheric $\mathrm{CO}_{2}$ over the last century has already led to a reduction in ocean $\mathrm{pH}$ (ocean acidification) and an increase in ocean temperature ${ }^{4}$. Dissolved $\mathrm{CO}_{2}$ levels in the ocean are rising in line with atmospheric $\mathrm{CO}_{2}^{5}$ and are projected to exceed $900 \mu \mathrm{atm}$ from the current day $390 \mu \mathrm{atm}$ by $2100^{6}$, while temperatures of the coastal ocean may increase by up to $3^{\circ} \mathrm{C}^{4}$. Coral reefs are particularly susceptible to these changes as they have evolved under relatively stable environmental conditions and many organisms may live near their maximum physiological tolerance limits for temperature and $\mathrm{CO}_{2}{ }^{7,8}$. How reef communities are affected will be dependent on the ability of species to tolerate or adapt to the new conditions and how the altered characteristics of species influence the outcomes of key processes, such as competition and predation'.

Elevated levels of $\mathrm{CO}_{2}$ affect the acid-base balance of marine organisms ${ }^{10}$ and alters the processing of sensory information for organisms as diverse as snails, crabs and fishes ${ }^{11-13}$. For fishes this effect occurs through modification to the functioning of neuroreceptors ${ }^{14}$, which changes the way individuals interact with their habitats and with predators, leading to increased levels of mortality, particularly at critical life history bottlenecks such as settlement ${ }^{15,16}$. While research demonstrates major changes in behaviour and performance for isolated individuals, it is unknown how these conditions are likely to influence the biological interactions that form the foundation of community dynamics.

Ocean acidification and elevated water temperature also affect the live coral that is an important source of shelter and food for many coral reef fishes. High $\mathrm{CO}_{2}$ leads to a reduction in seawater $\mathrm{pH}$ that decreases the availability of carbonate ions required for coral skeleton growth ${ }^{17}$. In addition, ocean warming causes corals to lose the symbiotic zooxanthellae that produce much of their required food ${ }^{18}$. This coral bleaching has been responsible for wide scale loss of coral, and combined with the effect of storms has resulted in widespread degradation of live coral and the fish communities that associate with them ${ }^{19-21}$. While shifts in fish community composition have been associated with coral degradation, it is unclear how degraded reef habitat will affect interactions among fishes that live in these environments in a high $\mathrm{CO}_{2}$ world.

Marine fishes display inter- and intra-specific variability in the extent to which they are affected by $\mathrm{CO}_{2}$-driven modifications to their environment. While many species require live bushy coral as a nursery habitat ${ }^{19,22}$, many have the flexibility to satisfy their resource requirements from a broader resource base and are not confined to one habitat (often classed as habitat generalists). Moreover, some fish species are more susceptible than others to the effects of elevated $\mathrm{CO}_{2}{ }^{16,23}$, and even within species there can be high variability in the degree to which sensory systems are compromised ${ }^{13}$. This variability in the way species are affected modifies the selection profiles by predators on juvenile fishes under moderately elevated $\mathrm{CO}_{2}\left(\sim 800-900 \mu \mathrm{atm} \mathrm{CO}_{2}\right)^{24-26}$. One of the fundamental processes that affect the susceptibility of individuals to predation is how the prey within a multispecies assemblage 
interact to modify individual risk. Interference competition, is particularly important in affecting the small scale distribution of growth, body size, body condition and distribution in relation to predation risk $^{27,28}$. While there are some studies demonstrating differences in sensitivity to $\mathrm{CO}_{2}$ among damselfish species, it is unclear how these differences may affect behavioural interactions under natural conditions of predation risk.

These effects will not occur in isolation, but rather as the coral habitats degrade fishes that inhabit these habitats will themselves be battling to adapt physiologically to the new resources and balance of senses available to them for risk assessment ${ }^{29}$. Our study examined how $\mathrm{CO}_{2}$ levels projected to occur in the next 70-100 y may affect the interactions between two damselfish species known to compete for space at settlement ${ }^{28}$ and how these interactions were modified in coral habitat degraded through bleaching. First, we reared wildcaught damselfish larvae of the two species (Pomacentrus amboinensis and $P$. moluccensis) in elevated $\mathrm{CO}_{2}(945 \mu \mathrm{atm})$ or control water for 4 days, which we have previously shown to be sufficiently long to yield the lasting behavioural effects associated with $\mathrm{CO}_{2}$-induced neuroreceptor modification ${ }^{14,15}$. Secondly, we transplanted treated fish to an array of natural reefs made of unbleached or bleached hard coral in a $2 \times 2$ design to test if exposure to elevated $\mathrm{CO}_{2}$ and coral state interacted to alter the behaviour of fishes and their risk of mortality during recruitment to adult habitat. Because $\mathrm{CO}_{2}$ impairs the senses used to detect and respond to habitat characteristics and assess predation ${ }^{15,30}$, we predicted that the effects of $\mathrm{CO}_{2}$ might interact with habitat state to affect behaviour and ultimately survival. Our results show that elevated $\mathrm{CO}_{2}$ reverses the competitive outcome between the two species with mortal consequences and that this reversal is accentuated in degraded habitats.

\section{Results}

There was a significant difference in mortality of $P$. moluccensis among the four treatments $\left(\mathrm{X}^{2}=20.05, \mathrm{df}=3, \mathrm{p}=0.0002\right)$. Fish from elevated $\mathrm{CO}_{2}$ on unbleached coral had approximately four times the survival of fish from the other three treatments (Fig. 1a), indicating that there was an interaction between $\mathrm{CO}_{2}$ treatment and coral state. Mortality curves for $P$. amboinensis also differed from one another $\left(X^{2}=36.7728, \mathrm{df}=3, \mathrm{p}<0.0001\right)$, with fish that had been exposed to elevated $\mathrm{CO}_{2}$ having lower survival than those from current day $\mathrm{CO}_{2}$ conditions (Fig. 1b). Those exposed to elevated $\mathrm{CO}_{2}$ on bleached coral died within $48 \mathrm{~h}$, while over $50 \%$ of fish from present day $\mathrm{CO}_{2}$ conditions survived $72 \mathrm{~h}$ (Fig. 1b).

The maximum distance fishes ventured away from the coral shelter was affected by coral state and differed between species, but this species-specific effect was largely reversed with elevated $\mathrm{CO}_{2}$ (Species $\times$ State $\times \mathrm{CO}_{2}$ treatment: $\mathrm{F}_{1,208}=5.10, \mathrm{p}=0.025$; Fig. $\left.2 \mathrm{a}\right)$. On unbleached coral at ambient $\mathrm{CO}_{2}$, both species stayed a similar distance from the coral. However, on bleached coral, P. moluccensis was over twice as far from shelter than $P$. amboinensis. The trends between species were largely reversed by elevated $\mathrm{CO}_{2}$ conditions (Fig. 2b). On healthy coral P. moluccensis stayed closer to the coral, at a distance that did not differ from ambient $\mathrm{CO}_{2}$ condition. In contrast, $P$. amboinensis was located almost 4 times as far from unbleached coral than when exposed to ambient $\mathrm{CO}_{2}$ conditions, and twice as far from the unbleached coral than P. moluccensis. These trends were accentuated when the patch reef comprised of bleached coral (Fig. 2b). The height of fish on patch reefs differed between species, but the magnitude of the effect changed with $\mathrm{CO}_{2}$ conditions experienced (Species $\times \mathrm{CO}_{2}$ treatment: $\mathrm{F}_{1,208}=12.31, \mathrm{p}$ $<0.0006)$. P. amboinensis occupied the lower part of the patch regardless of $\mathrm{CO}_{2}$ treatment or coral state, while P. moluccensis occupied the highest part of the reef, but was significantly closer to the bottom when fish had been exposed to elevated $\mathrm{CO}_{2}$ (Tukey's test, $\mathrm{p}$ $<0.05$; Fig. 3).
The levels of aggression exhibited by fish to their size-matched pair was strongly affected by coral state and differed between species, but this species-specific effect was reversed with elevated $\mathrm{CO}_{2}$ (Species $\times$ State $\times \mathrm{CO}_{2}$ treatment: $\mathrm{F}_{1,208}=11.757, \mathrm{p}=0.0007$; Fig. 4). Under ambient $\mathrm{CO}_{2}$ conditions, $P$. amboinensis was much more aggressive than $P$. moluccensis with the dominant $P$. amboinensis being more aggressive on bleached coral (Fig. 4a). In contrast, under elevated $\mathrm{CO}_{2}$ conditions the pattern was reversed by species, with $P$. moluccensis being most aggressive on bleached coral compared to unbleached coral, but always more aggressive than P. amboinensis (Fig. 4b).

\section{Discussion}

Elevated $\mathrm{CO}_{2}$ affected the outcome of competitive interactions between species, with a complete reversal in the species that was the most aggressive and dominant competitor. This reversal in the outcome of interference competition was most dramatic on degraded, bleached coral. The mechanism underlying this change was the differential effect of $\mathrm{CO}_{2}$ on the behaviour of the two species. A previous laboratory study has shown that $P$. moluccensis is less susceptible to exposure to elevated $\mathrm{CO}_{2}$ conditions than its congener P. amboinensis ${ }^{16}$, who is the competitive dominant under present day conditions ${ }^{28}$. For fish exposed to either current day or future $\mathrm{CO}_{2}$ conditions, the competitive interactions indirectly had mortal consequences because the aggressive interactions pushed the subordinate into areas of higher risk away from shelter; a pattern accentuated on degraded coral. The behavioural changes found in our study suggest that elevated $\mathrm{CO}_{2}$ may result in changes in the way species interact with each other and this will alter the processes that shape communities and ecosystems.

Understanding how altered species interactions affect communities and ecosystems is fundamental to predicting the impacts of climate change and ocean acidification ${ }^{1,31}$. Previous studies on benthic communities have observed enhanced competitive dominance of algae over corals under elevated $\mathrm{CO}_{2}{ }^{3,9}$. In contrast, our results show a reversal of competitive dominance, indicating that ocean acidification may lead to far more complex outcomes than would be predicted with just enhanced competitive effects. Competitive reversals between species should be commonplace under natural circumstances $^{32}$ for organisms with strong competitive asymmetry to coexist, however they are seldom conclusively demonstrated. Steneck et al. (1991) found that depth determined which of two species of crustose coralline algae was competitively dominant, but dominance was reversed when grazing limpets reduce fitness of one species ${ }^{33}$. Under present day $\mathrm{CO}_{2}$ conditions, McCormick and Weaver (2012) found that who won the contest between $P$. amboinensis and $P$. moluccensis was strongly asymmetrical and dependent on size, over-and-above other ecological factors such as prior residency ${ }^{28}$. The importance of size in dictating the outcome of competitive contests is a common finding for many organisms ${ }^{34}$. P. moluccensis juveniles only started to win contests when they were $1.2 \mathrm{~mm}$ larger than P. amboinensis. Because the winner of competitive interactions is based on body size, the stochasticity of recruitment at small spatial scales $^{35}$ and its pulsed nature within a tropical recruitment season ${ }^{36}$ will mean that neither species will always win or lose. This may lead to a destabilizing influence on the competitive dominance of any one species, making competitive exclusion less likely.

It holds therefore that changes in the competitive outcome will also occur when the species change in their ability to defend a limited resource. Studies that have examined the effect of $\mathrm{CO}_{2}$ on the behaviour of solitary damselfish juveniles demonstrate that they display a willingness to take more risk, they fail to learn predators, and as a result die faster than control fish ${ }^{15,24,37}$. However, the ability to cope with elevated $\mathrm{CO}_{2}$ varies among closely related species. Ferrari et al. (2011a) exposed 5 different species of damselfish from the genus Pomacentrus to damage-released chemical alarm cues 


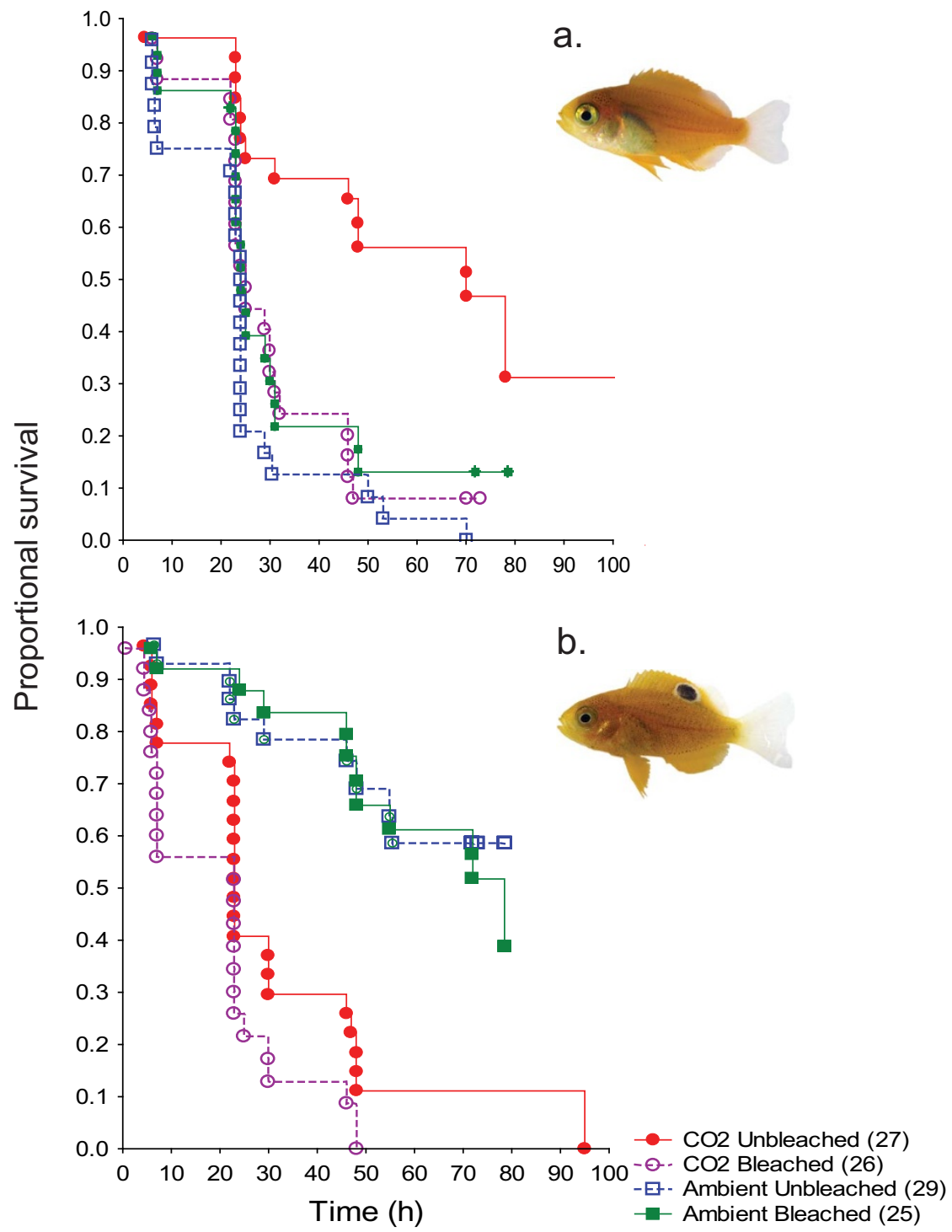

Figure 1 Influence of competition on survival. Effects of interspecific competition on the proportional survival of (a) Pomacentrus moluccensis and (b) P. amboinensis on unbleached or bleached coral habitats when exposed to elevated or current day $\mathrm{CO}_{2}$ levels. Kapalin-Meier survival trajectories illustrate the different survival trajectories on patches of live unbleached or live-bleached Pocillopora damicornis hard coral. Individual fish were placed in size-matched pairs on the habitats $(\mathrm{n}=25-29)$. Photographs: Mark McCormick.

from conspecifics ${ }^{16}$. Fish held at current day $\mathrm{CO}_{2}$ levels all responded with a fright response to the alarm cues, while those acclimated to higher $\mathrm{CO}_{2}$ levels exhibited different species-specific responses from no response to the alarm cues, through to a fright response that was little different from the controls. Further, in a mesocosm study, Ferrari et al. (2011b) found that the relative mortality through predation of 5 species of damselfishes changed when both predator and prey had been exposed to elevated $\mathrm{CO}_{2}^{24}$. However, the lack of behavioural information meant that the mechanism underlying the result was unclear. Our study shows that $P$. amboinensis exposed to elevated $\mathrm{CO}_{2}$ also becomes less aggressive and avoids similar sized competitors that they would normally have dominated. This lowering of aggression, which underlies interference competition, is critically important for the fish to maintain its status in the plankton feeding community and will have repercussions for such ecologically important activities as obtaining food of the highest possible quality and the acquisition and defence of spawning sites.

Species are likely to acclimate to some extent to the modified chemical conditions found in future $\mathrm{CO}_{2}$ conditions. However, previous studies have shown that the behavioural responses of juvenile damselfish are the same in individuals kept for 4 days at elevated $\mathrm{CO}_{2}$ and those reared from hatching at the same $\mathrm{CO}_{2}$ levels ${ }^{15,30}$. Therefore, there seems to be limited prospects for within-generation acclimation of behavioural changes caused by exposure to high $\mathrm{CO}_{2}$, at least during the critical early life history stages investigated here. In one of the only transgenerational studies to date, Miller et al. (2012) found that the routine metabolic rate, growth and survival of F1 offspring of the clownfish, Amphiprion melanopus, exposed to $1032 \mu \mathrm{atm}$ returned to levels found in control fish as a result of non-genetic parental effects ${ }^{38}$. The generality of this result is unknown but likely to vary among species. Interestingly, a recent study has demonstrated that damselfish may have limited ability to compensate for $\mathrm{CO}_{2}$-induced behavioural changes through parental effects over one generation ${ }^{39}$. The ability of the species used in the current study to acclimate over multiple generations by non-genetic parental effects is currently unknown, however, it is likely that competing species who have been differentially affected by $\mathrm{CO}_{2}$ will be a realistic situation in the future.

$\mathrm{CO}_{2}$ appears to affect early life history traits such as respiration and growth in a different way to behaviour. Currently it is unknown for any species whether behaviour is likely to adapt over generations 


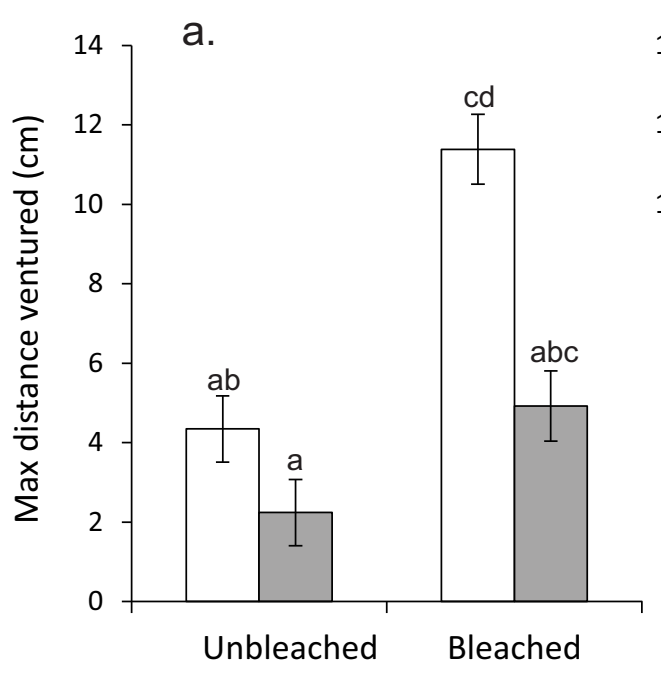

Ambient $\mathrm{CO}_{2}$ b.

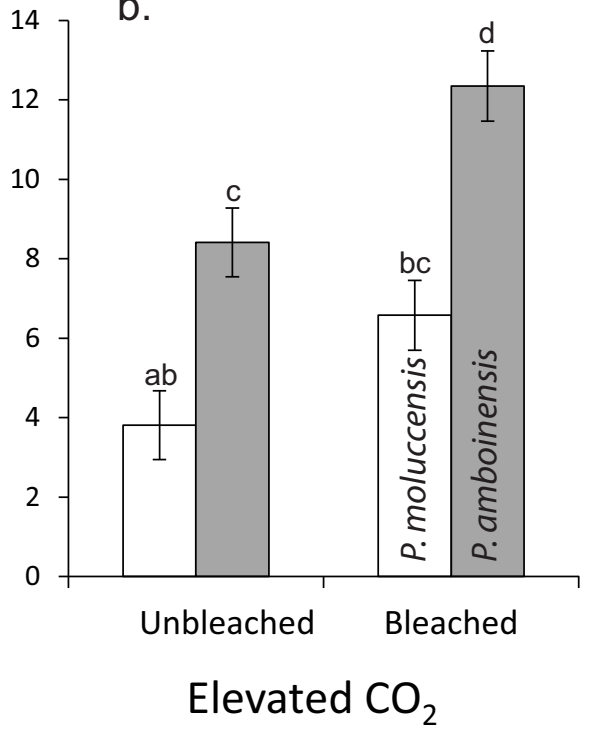

Figure $2 \mid$ Influence of exposure to elevated $\mathrm{CO}_{2}$ and habitat type on shelter use. The mean maximum distance that fishes ventured from the shelter of unbleached or bleached hard coral within 3 min behavioural observations for Pomacentrus moluccensis (white) and P. amboinensis (grey) that had been reared under ambient or elevated $\mathrm{CO}_{2}$ conditions. Letters above the bars represent Tukey's HSD groups. Error bars are standard errors $(\mathrm{n}=26-29)$.

to elevated $\mathrm{CO}_{2}$. Recent studies of marine fishes and invertebrates have shown that at least part of the behavioural effect of elevated $\mathrm{CO}_{2}$ appears to occur through a change in the gradient of acid-base relevant ions across the neuron membrane ${ }^{40}$. This leads to a change in the operation of neuroreceptors (GABA-A receptors), switching them from an inhibitory to excitatory role. Research is required to determine whether this neural mechanism can adapt over multiple generations before the full ramifications of the present study can be determined.

Behavioural effects of high $\mathrm{CO}_{2}$ will not occur in isolation; ocean warming that affects the health of corals that fish use as shelter ${ }^{20}$ also has direct effects on the performance of interacting fish species. A number of recent studies have found that juvenile fish that use live coral as a nursery habitat move further away from the shelter when the coral is bleached, and this exposes them to higher predation

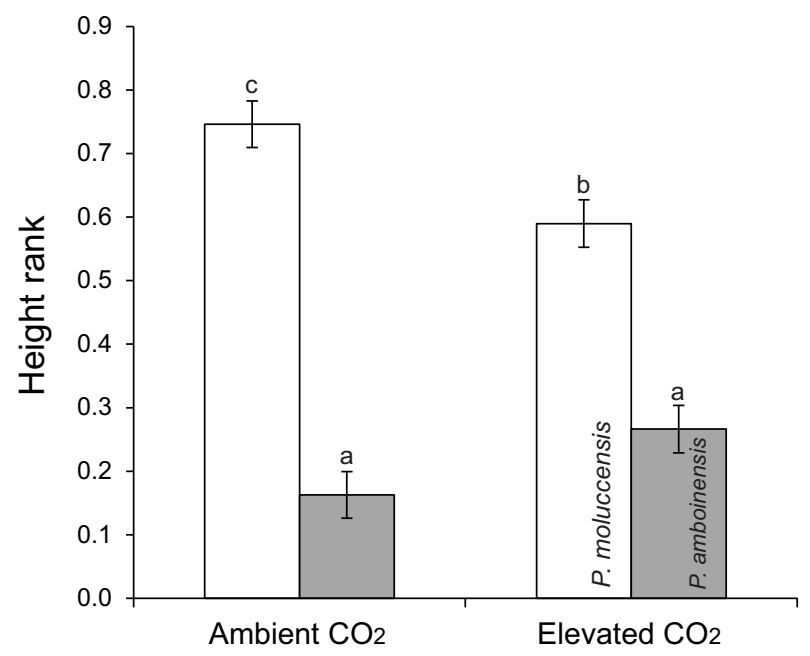

Figure 3 Influence of exposure to elevated $\mathrm{CO}_{2}$ and fish species on space use. Mean proportional height above the reef base within $3 \mathrm{~min}$ behavioural observations for Pomacentrus moluccensis (white) and $P$. amboinensis (grey) that had been reared under ambient or elevated $\mathrm{CO}_{2}$ conditions. Letters above the bars represent Tukey's HSD groups. Error bars are standard errors $(n=53-55)$. pressure in the laboratory ${ }^{41}$ and field ${ }^{28,42,43}$. The movement away from bleached corals was also found in the current study, with the subordinate species being furthest away from shelter. This was in part driven by an increase in the aggression by the dominant species, the identity of which changed in response to elevated $\mathrm{CO}_{2}$. Ocean warming may be expected to accentuate this effect by elevating routine metabolic rates ${ }^{40}$, increasing activity ${ }^{44,45}$, and the daily food requirements ${ }^{46}$, though some of this effect may be reduced through developmental and parental acclimation ${ }^{47,48}$.

Our results represent a first step towards an understanding of how community processes may change in response to elevated $\mathrm{CO}_{2}$. Future studies will also need to incorporate $\mathrm{CO}_{2}$ effects on predators, who themselves could be variously affected ${ }^{49}$. As demonstrated in the present study, competition can affect survival by altering an individual's exposure to predators, either directly through aggression pushing subordinates into riskier habitats, or indirectly by elevating hunger in subordinates and in so doing influencing their balance between foraging and vigilance ${ }^{50}$. Because both intra- and inter-specific competition is critically important in influencing prey vulnerability to predators investigation of the three-way interaction between dominant, subordinate and predator under elevated $\mathrm{CO}_{2}$ will be the next crucial step in understanding the regulation of communities in a high $\mathrm{CO}_{2}$ ocean.

\section{Methods}

Newly settled ambon damselfish, Pomacentrus amboinensis (Pomacentridae), and lemon damselfish, $P$. moluccensis compete for shelter in the same live coral living space when they first settle from the plankton ${ }^{51}$. Both are planktivores and show similar preferences for live, healthy coral at settlement ${ }^{28}$. Interaction with the other species at the reef edge reduces the growth of both species compared to locations where the other species is absent ${ }^{28}$. Within 2 mo on shallow reefs the two species display a disjunct distribution patterns with $P$. amboinensis associated with the base of the reef and $P$. moluccensis with live coral at the top of the reef ${ }^{28}$.

Settlement-stage larvae of $P$. amboinensis and $P$. moluccensis were collected overnight using light traps (for design see Meekan et al. 2001 ${ }^{52}$ ) moored in open water around Lizard Island $\left(14^{\prime} 40^{\circ} \mathrm{S}, 145^{\prime} 28^{\circ} \mathrm{E}\right)$, in the northern Great Barrier Reef, Australia. Fish were sorted to species and transferred to $35 \mathrm{~L}$ aquaria supplied with a continuous flow of either control (present day $\mathrm{CO}_{2} ; 410 \mu \mathrm{atm}$ ) or elevated- $\mathrm{CO}_{2}$ seawater ( $945 \mu \mathrm{atm}$; see Supplementary file) for 4 days. This period of time has been found to be sufficient to elicit the full extent of behavioural effects of high $\mathrm{CO}_{2}{ }^{15}$. Fish were fed 4 times daily ad libitum with newly hatched Artemia sp.

On the day of the field trial, fishes from the control and elevated- $\mathrm{CO}_{2}$ treatments were placed into individually labelled plastic bags of seawater and measured with digital callipers. For each $\mathrm{CO}_{2}$ treatment, interspecific pairs of $P$. amboinensis and 


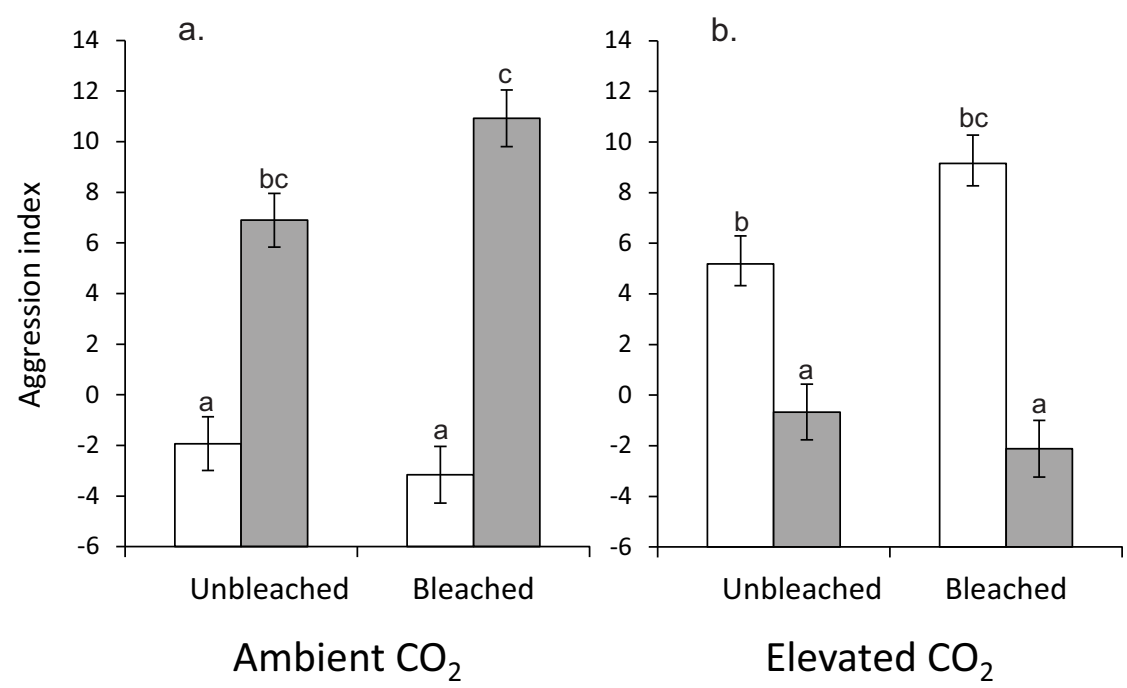

Figure $4 \mid$ Influence of exposure to elevated $\mathrm{CO}_{2}$ and habitat type on aggression. Level of aggression displayed by juvenile Pomacentrus moluccensis (white) and P. amboinensis (grey) 45-60 min after release in size matched pairs onto a patch of habitat (healthy unbleached or bleached live Pocillopora damicornis). Fishes were either reared under ambient or elevated $\mathrm{CO}_{2}$ conditions. Aggression Index is calculated as Displays $+(3 \times$ Bites $)-$ Avoidances. Letters above the bars represent Tukey's HSD groups. Errors are standard errors. $n=26-29$.

P. moluccensis were created such that the size difference between fishes was no more than $0.3 \mathrm{~mm}$ SL. Fish length was standardised as it has been found to be important in determining the outcome of interaction between newly settled fishes and their survival $^{53,54}$. There was no significant difference in size of the fish between species used in the experiment (mean \pm se: P. amboinensis $11.4 \pm 0.03 ;$ P. moluccensis $11.5 \pm 0.03$; $\left.\mathrm{F}_{1,214}=3.3, \mathrm{p}=0.07\right)$. To reduce transport and handling stress, fish in bags were transported to the field site in a $60 \mathrm{~L}$ holding tank of seawater (to reduce temperature fluctuations) under subdued light conditions.

Patch reefs used in the field experiment were composed of one of two states of the bushy hard coral, Pocillopora damicornis: live unbleached coral or bleached coral. Bleached coral was produced by collecting healthy coral and placing it in freshwater for 4 minutes $^{5}$. Over the next $48 \mathrm{~h}$ stressed coral lost their zooxanthellae and became pale in colouration but still had their tissue intact. An array of patch reefs $(\sim 18 \times 15$ $\times 18 \mathrm{~cm}$ ) was constructed on a sandflat, arranged 4-5 m apart and 3-6 m away from continuous reef.

Both damselfish species naturally settle on patch reefs near continuous reef. In this habitat juveniles are exposed to a diverse range of predators that use a variety of feeding modes from ambush (lizardfish Synodus dermatogenys and small cods Cephalopholis microprion) to pursuit (dottybacks Pseudochromis fuscus and wrasse Thalassoma lunare). These fishes can be observed preying on juveniles that venture too far from shelter.

Experimental protocol. Length-matched pairs of $P$. amboinensis and P. moluccensis were placed onto unbleached or bleached coral patches. Patches were cleared of any other fishes or invertebrates using a hand net prior to release. Experimental fishes were released on natural reefs away from the study area. A small wire cage $(\sim 30 \times 30$ $\times 30 \mathrm{~cm}, 12 \mathrm{~mm}$ mesh size) was placed over the patch to allow fish to acclimatise to their new surroundings while being protected from predators. Cages were removed 40 to $60 \mathrm{~min}$ after release of the fish between 10:00 and 12:00 h. Fish presence was monitored 2 to 3 times per day (i.e. after the initial acclimatisation period, the evening after release and the following morning) for $\sim 72 \mathrm{~h}$. The field experiment and monitoring of survival were conducted over a continuous $11 \mathrm{~d}$ period during a recruitment pulse in late October 2012. Water temperature during the census periods averaged $25.5^{\circ} \mathrm{C}$. Our previous studies with tagged fish have shown that settlement stage damselfish do not migrate from these isolated reefs and that any loss is most parsimoniously attributed to predation (e.g. $\left.{ }^{42,44}\right)$. This research was conducted under animal ethics approval from JCU (Approval A1737) and a research permit from the Great Barrier Reef Marine Park Authority (G12-34811.1).

Behavioural assessment. The behaviour of each fish placed on the patch reefs was monitored 45 to $60 \mathrm{~min}$ after placement on the reef following the protocol of McCormick (2009) ${ }^{42}$. Briefly, behaviour of the focal fish was assessed over a $3 \mathrm{~min}$ period by a scuba diver positioned $1.0 \mathrm{~m}$ away from the patch with the aid of a magnifying glass. Six aspects of activity and behaviour were assessed: a) maximum distance ventured from the habitat patch; $b$ ) height above substratum (categorized as $\%$ of the time spent within the bottom, middle or upper third of the patch); c) number of fin displays; d) the number of chases or bites; e) number of avoidance episodes in response to a conspecific approach. Two additional composite variables were created to summarize several of the variables recorded and enhance ecological interpretation. Relative height on the patch was summarized as a cumulative proportion of the time spent at varying heights over the $3 \mathrm{~min}$ observation period, with the top of the patch taken as height of 1 , mid-patch a height of 0.5 , and bottom a height of 0 . For instance, when a fish spends $50 \%$ of its time at the top of the patch, $20 \%$ at the middle and $30 \%$ at the base the relative height value would be: $(1 \times 0.5)+(0.5 \times 0.2)+(0 \times 0.3)=$ 0.6 . An aggression index was also created by adding the number of displays to the product of three times the number of chases/bites and then subtracting the number of avoidance event ${ }^{28,42}$. Our other studies have shown that a $3 \mathrm{~min}$ observation period is sufficient to quantify behaviour because it is consistent in the short term (10 min to 5 days ${ }^{44}$ ). The variable measured had been previously shown to be sensitive to competitive interactions between these two fish specie ${ }^{28,43}$.

Statistical analyses. Survival (up to $72 \mathrm{~h}$ ) of fish among the $\mathrm{CO}_{2}$ treatment (ambient and elevated) by habitat (unbleached, bleached) combinations were compared using multiple-sample Survival Analysis, which uses a Cox's proportional hazard model (Statistica $12.0^{56}$ ). This regression model is not based on any assumptions concerning the nature or shape of the underlying survival distribution. Survival curves of each $\mathrm{CO}_{2}$ treatment and coral state were calculated and plotted using the Kaplan-Meier product-limit method. The Kaplan-Meier method is a non-parametric estimator of survival that incorporates incomplete (censored) observations, such as those cases where censuses had to be terminated on trials prior to their completion due to time limitations of a field trip.

Three behavioural variables, maximum distance ventured, relative height and the aggression index, were compared between species, coral habitat and $\mathrm{CO}_{2}$ treatment combinations with three-factor ANOVA (Type III SS) followed by Tukey's HSD tests. Residual analysis was used to examine assumptions of ANOVA.

1. Harley, C. D. G. Climate change, keystone predation, and biodiversity loss. Science 334, 1124-1127 (2011)

2. Russell, B. D. et al. Predicting ecosystem shifts requires new approaches that integrate the effects of climate change across entire systems. Biol. Let. 8, 164-166 (2012).

3. Kroeker, K. J., Micheli, F. \& Gambi, M. C. Ocean acidification causes ecosystem shifts via altered competitive interactions. Nature Climate Change 3, 156-159 (2013).

4. Meehl, G. A. et al. Climate Change 2007: the physical science basis. Contribution of working group I to the fourth assessment report of the intergovernmental panel on climate change. Solomon, S., Qin, D., Manning, M., Chen, Z., Marquis, M., Averyt, K. B., Tignor, M., Miller, H. L. (ed.) 747-846 (Cambridge, U. K., Cambridge University Press, 2007).

5. Doney, S. C. The growing human footprint on coastal and open-ocean biogeochemistry. Science 328, 1512-1516 (2010).

6. Meinshausen, M. et al. The RCP greenhouse gas concentrations and their extensions from 1765 to 2300. Climatic Change 109, 213-241 (2011).

7. Hoegh-Guldberg, O. et al. Coral reefs under rapid climate change and ocean acidification. Science 318, 1737-1742 (2007)

8. Pörtner, H. O. \& Farrell, A. P. Physiology and climate change. Science 322, 690-692 (2008).

9. Diaz-Pulido, G., Gouezo, M., Tilbrook, B., Dove, S. \& Anthony, K. R. N. High $\mathrm{CO}_{2}$ enhances the competitive strength of seaweeds over corals. Ecol. Let. 14, 156-162 (2011).

10. Pörtner, H. O., Mark, F. C. \& Bock, C. Oxygen limited thermal tolerance in fish? Answers obtained by nuclear magnetic resonance techniques. Resp. Physiol. Neurobiol. 141, 243-260 (2004). 
11. Watson, S.-A. et al. Marine mollusc predator-escape behaviour altered by nearfuture carbon dioxide levels. Proc. R. Soc. Lond. b (2013) doi: 10.1098/ rspb.2013.2377.

12. Briffa, M., de la Haye, K. L. \& Munday, P. L. High $\mathrm{CO}_{2}$ and marine animal behaviour: Potential mechanisms and ecological consequences. Mar. Poll. Bull. 64, 1519-1528 (2012).

13. Munday, P. L., McCormick, M. I. \& Nilsson, G. E. Impact of global warming and rising $\mathrm{CO}_{2}$ on coral reef fishes: what hope for the future? J. Exp. Biol. 215, 3865-3873 (2012).

14. Nilsson, G. E. et al. Near-future $\mathrm{CO}_{2}$ levels alter fish behaviour by interference with neurotransmitter function. Nature Climate Change 2, 201-204 (2012).

15. Munday, P. L. et al. Ocean acidification alters larval behaviour and impairs recruitment to reef fish populations. PNAS 107, 12930-12934 (2010).

16. Ferrari, M. C. O. et al. Intrageneric variation in tolerance of coral reef fishes to ocean acidification: implications for climate change projections on marine communities. Global Change Biol. 17, 2980-2986 (2011a).

17. Crook, E. D., Cohen, A. L., Rebolledo-Vieyra, M., Hernandez, L. \& Paytan, A. Reduced calcification and lack of acclimatization by coral colonies growing in areas of persistent natural acidification. Proc. Natl. Acad. Sci. U. S. A. 110 11044-11049 (2013).

18. Oliver, J. K., Berkelmans, R. \& Eakin, C. M. Coral bleaching in space and time. Coral Bleaching: Patterns, Processes, Causes and Consequences, Ecological Studies. van Oppen, M. J. H., Lough, J. M. (ed.) 139-158 (Springer, London, 2009).

19. Jones, G. P., McCormick, M. I., Srinivasan, M. \& Eagle, J. V. Coral decline threatens fish biodiversity in marine reserves. PNAS 101, 8251-8253 (2004).

20. Pratchett, M. S. et al. Effects of climate-induced coral bleaching on coral-reef fishes - ecological and economic consequences. Oceanogr. Mar. Biol. 46, 251-296 (2008).

21. Osborne, K., Dolman, A. M., Burgess, S. C. \& Johns, K. A. Disturbance and the dynamics of coral cover on the Great Barrier Reef (1995-2009). PLoS ONE 6 , e17516 (2011).

22. Gilmour, J. P., Smith, L. D., Heyward, A. J., Baird, A. H. \& Pratchett, M. S Recovery of an isolated coral reef system following severe disturbance. Science 340, 69-71 (2013)

23. Couturier, C. S., Stecyk, J. A. W., Rummer, J. L., Munday, P. L. \& Nilsson, G. E. Species-specific effects of near-future $\mathrm{CO}_{2}$ on the respiratory performance of two tropical prey fish and their predator. Comp. Biochem. Physiol. 166, 482-489 (2013).

24. Ferrari, M. C. O. et al. Putting prey and predator into the $\mathrm{CO}_{2}$ equation quantitative and qualitative effects of ocean acidification on predator-prey interactions. Ecol. Let. 14, 1143-1148 (2011b).

25. Munday, P. L. et al. Selection for $\mathrm{CO}_{2}$ tolerance in marine fishes. Ocean Acid 1, 1-5 (2012).

26. Allan, B. J. M., Domenici, P., McCormick, M. I. \& Munday, P. L. Elevated $\mathrm{CO}_{2}$ affects predator-prey interactions through altered performance. PLOS ONE 8, e58520 (2013).

27. Holbrook, S. J. \& Schmitt, R. J. Competition for shelter space causes densitydependent predation mortality in damselfishes. Ecology 83, 2855-2868 (2002)

28. McCormick, M. I. \& Weaver, C. It pays to be pushy: intracohort interference competition between two reef fishes. PLoS ONE 7, e42590 (2012).

29. Lönnstedt, O. M., McCormick, M. I. \& Chivers, D. P. Degraded coral disrupts innate antipredator responses of fish. Ecol. Evol. 3, 38-47 (2013).

30. Dixson, D. L., Munday, P. L. \& Jones, G. P. Ocean acidification disrupts the innate ability of fish to detect predator olfactory cues. Ecol. Let. 13, 68-75 (2010).

31. Doney, S. C. et al. Climate change impacts on marine ecosystems. Ann. Rev. Mar. Sci. 4, 11-37 (2012).

32. Connell, J. H. On the prevalence and relative importance of interspecific competition: evidence from field experiments. Am. Nat. 122, 661-683 (1983).

33. Steneck, R. S., Hacker, S. D. \& Dethier, M. N. Mechanisms of competitive dominance between crustose coralline algae - an herbivore-mediated competitive reversal. Ecology 72, 938-950 (1991).

34. Schoener, T. W. Field experiments on interspecific competition. Am. Nat. 122 240-285 (1983).

35. Doherty, P. J. \& Williams, D. M. The replenishment of coral reef fish populations. Oceanogr. Mar. Biol. Annu. Rev. 26, 487-551 (1988).

36. Milicich, M. J. \& Doherty, P. J. Larval supply of coral reef fish populations: magnitude and synchrony of replenishment to Lizard Island, Great Barrier Reef. Mar. Ecol. Prog. Ser. 110, 121-134 (1994)

37. Ferrari, M. C. O. et al. Effects of ocean acidification on learning in coral reef fishes. PLoS ONE 7, e31478 (2012).

38. Miller, G. M., Watson, S., Donelson, J. M., McCormick, M. I. \& Munday, P. L. Parental effects mediate impacts of elevated $\mathrm{CO}_{2}$ and global warming on a coral reef fish. Nature Climate Change 2, 858-861 (2012).
39. Allan, B. J. M., Miller, G. M., McCormick, M. I., Domenici, P. \& Munday, P. L. (submitted) Parental effects improve escape performance of juvenile reef fish in a high $\mathrm{CO}_{2}$ world. Proc. R. Soc. Lond. b.

40. Nilsson, G., Crawley, N., Lunde, I. G. \& Munday, P. L. Elevated temperature reduces the respiratory scope of coral reef fishes. Global Change Biol. 15, 1405-1412 (2009).

41. Coker, D. J., Pratchett, M. S. \& Munday, P. L. Coral bleaching and habitat degradation increase susceptibility to predation for coral-dwelling fishes. Behav. Ecol. 20, 1204-1210 (2009).

42. McCormick, M. I. Behaviourally mediated phenotypic selection in a disturbed coral reef environment. PLoS ONE 4, e7096 (2009).

43. McCormick, M. I. Lethal effects of habitat degradation on fishes through changing competitive advantage. Proc. R. Soc. Lond. b 279, 3899-3904 (2012).

44. McCormick, M. I. \& Meekan, M. G. The importance of attitude: the influence of behaviour on survival at an ontogenetic boundary. Mar. Ecol. Prog. Ser. 407, 173-185 (2010)

45. Biro, P. A., Beckmann, C. \& Stamps, J. A. Small within-day increases in temperature affects boldness and alters personality in coral reef fish. Proc. R. Soc. Lond. $b$ 277,71-77 (2009).

46. Bernreuther, M., Herrmann, J. P., Peck, M. A. \& Temming, A. Growth energetics of juvenile herring, Clupea harengus L.: food conversion efficiency and temperature dependency of metabolic rate. J. Appl. Ichthy. 29, 331-340 (2013).

47. Donelson, J. M., Munday, P. L., McCormick, M. I. \& Nilsson, G. E. Acclimation to predicted ocean warming through developmental plasticity in a tropical reef fish. Global Change Biol. 17, 1712-1719 (2011)

48. Donelson, J. M., Munday, P. L., McCormick, M. I. \& Pitcher, C. R. Rapid transgenerational acclimation of a tropical fish to climate change. Nature Climate Change 2, 30-32 (2012).

49. Cripps, I. L., Munday, P. L. \& McCormick, M. I. Ocean acidification affects prey detection by a predatory reef fish. PLoS ONE 6, e22736 (2011).

50. Lönnstedt, O. M., McCormick, M. I., Meekan, M. G., Ferrari, M. C. O. \& Chivers, D. P. Learn and live: the role of predator experience in influencing prey behaviour and survival. Proc. R. Soc. Lond. b 279, 2091-2098 (2012).

51. McCormick, M. I., Moore, J. A. Y. \& Munday, P. L. Influence of habitat degradation on fish replenishment. Coral Reefs 29, 537-546 (2010).

52. Meekan, M. G., Wilson, S. G., Halford, A. \& Retzel, A. A comparison of catches of fishes and invertebrates by two light trap designs, in tropical NW Australia. Mar. Biol. 139, 373-381 (2001)

53. Holmes, T. H. \& McCormick, M. I. Influence of prey body characteristics and performance on predator selection. Oecologia 159, 401-413 (2009).

54. Perez-Dominguez, R. \& Munch, S. B. Extreme selection on size in the early lives of fishes. Evolution 64, 2450-2457 (2010).

55. Coker, D. J., Pratchett, M. S. \& Munday, P. L. Influence of coral bleaching, coral mortality and conspecific aggression on movement and distribution of coraldwelling fish. J. Exp. Mar. Biol. Ecol. 414, 62-68 (2012).

56. Cox, D. R. Regression models and life tables. J. Roy. Stat. Soc. 34, 187-220 (1972).

\section{Acknowledgments}

Logistic support was provided by staff at the Lizard Island Research Station (Australian Museum). Cecilia Villa-Corta-Rath and Matthew Mitchell assisted MIM with the field component of the study. Oona Lonnstedt provided useful comments on a draft of the manuscript. Funding was provided through the ARC Centre of Excellence for Coral Reef Studies (CE0561432).

\section{Author contributions}

M.I.M. designed the study. S.-A.W. operated the $\mathrm{CO}_{2}$ dosing system. M.I.M. undertook the fieldwork. M.I.M., P.L.M. and S.-A.W. wrote the paper.

\section{Additional information}

Supplementary information accompanies this paper at http://www.nature.com/ scientificreports

Competing financial interests: The authors declare no competing financial interests.

How to cite this article: McCormick, M.I., Watson, S.-A. \& Munday, P.L. Ocean acidification reverses competition for space as habitats degrade. Sci. Rep. 3, 3280; DOI:10.1038/srep03280 (2013).

This work is licensed under a Creative Commons AttributionNonCommercial-NoDerivs 3.0 Unported license. To view a copy of this license, visit http://creativecommons.org/licenses/by-nc-nd/3.0 